\title{
Research Article \\ Salivary biomarkers for diagnosing renal functions in patients with type 2 diabetes: A correlative study
}

\author{
Saritha Harish ${ }^{1,2}$, Manjula Shantaram*1,2 \\ ${ }^{1}$ Research Scholar, ${ }^{* 1}$ Professor, Department of Studies and Research in Biochemistry, Mangalore University, Jnana Kaveri Post \\ Graduate Centre, Chikka Aluvara, 571232 Kodagu, Karnataka, India \\ ${ }^{2}$ Diagnostic Laboratory, Primary Health Centre, ${ }^{* 2}$ Director I/c Student Welfare Mangalore University, Mangalagangothri, \\ Dakshina Kannada District, Karnataka, India. PIN: 574199 \\ (Received: September $2020 \quad$ Revised: October $2020 \quad$ Accepted: November 2020)
}

Corresponding author: Manjula Shantaram. Email: manjula59@gmail.com

\begin{abstract}
Introduction and Aim: One of the major complications of the diabetes is End Stage Renal Disease (ESRD). Thus, it is of utmost importance to conduct research on the diagnosis and management of diabetes mellitus (DM), as it is considered as a major public health issue. Both blood and urine samples are generally used in the diagnosis of DM. Though blood offers more advantages as a diagnostic tool in DM, there is a scope for the development of a noninvasive method for the regular monitoring of glucose and renal function test, since venipuncture induces psychological stress in the patients. The aim of the current study was to correlate blood and salivary renal biomarkers.

Materials and Methods: We classified the study subjects into three groups, healthy (Group 1), Type 2 diabetic (T2D) patients without nephropathy (Group 2) and T2D patients with nephropathy (Group 3). We carried out estimation of various parameters such as glucose and renal function tests in both blood and saliva of all the three groups.

Results: This study confirmed that many of the parameters studied in both blood and saliva showed good positive correlation. The changes in serum parameters are in agreement with that of the salivary parameters in healthy, T2D without nephropathy and T2D with nephropathy groups.

Conclusion: This study corroborated that the saliva can be a very potential indicative means to diagnose and manage diabetes and its complications. Therefore, saliva can be effectively used as a sample for measuring and controlling diabetes in near future.
\end{abstract}

Keywords: Type 2 Diabetes; saliva, blood, renal function test

\section{INTRODUCTION}

$\mathrm{D}$ iabetes mellitus (DM) is an oldest disease and chronic metabolic disorder characterized by high blood glucose (1). Based on whether it is either a result of deficiency of insulin or inefficiency to use the same, DM is classified in to type 1 (T1D) or 2 (T2D). Development of T1D and T2D occur due to destruction of beta cells of pancreas by antibodies and through insulin resistance, respectively (2). DM is more prevalent in both low- and middle-income countries, with increased number of individuals being affected (3). Thus, DM is one of the major public health concerns and is important to provide greater emphasis to study on its diagnosis and management.

Out of the total diabetic population, T2D accounts for approximately $90 \%$. Some of the common but important risk factors of T2D are age, obesity, diet, ethnicity, genetics and family history (3). The major hallmarks of the T2D are hyperglycemia (increased blood glucose), insulin resistance and insulin deficiency, which often lead to many short-term and long-term complications (4). These complications can be either microvascular or macrovascular and are the reasons for DM associated mortality and morbidity (1). Microvascular complications include retinopathy (affects retina), nephropathy (which affect kidney) and neuropathy (which affect peripheral nerves). Macrovascular complications include coronary artery disease, peripheral vascular disease and cerebrovascular disease. Cardiovascular diseases and stroke are the main cause for the mortality among T2D patients. As the number of people with diabetes is growing rapidly and is expected to be doubled in the next ten years, T2D is considered as one of the epidemics in some part of the world.

One of the major complications of the diabetes is End Stage Renal Disease (ESRD). It was observed that there has been progressive increase in the incidence and prevalence of CKD over the last thirty years (5). This is because of the rapid increase in the number of people with diabetes, thus DM is the main etiological factor of CKD. It is reported that about one-third and one-fifth of T1D and T2D subjects develop nephropathy in about 16 years, respectively. The onset of CKD remains undiagnosed for many years (5-10 years), whereas, the progression is often dependent on the blood glucose and blood pressure (6). End stage renal failure increases the level of urea nitrogen (BUN) and non-protein nitrogen in blood (7). Such accumulation of metabolic waste products leads to 
increase in the levels of various components of the blood including creatinine, urea and electrolytes.

Both blood and urine samples are generally used in the diagnosis of DM. Though blood offers more advantages as a diagnostic tool in DM, it requires a trained manpower and is relatively costly. Such conventional diagnosis and monitoring methods using venipuncture induces psychological trauma in the patients. Thus, development of a non-invasive method for the regular monitoring of glucose levels are very essential (8). In this regard, saliva is one of the best alternatives for blood, because of its non-invasive sample collection method and cost-effectiveness (9). Many studies have been carried out to evaluate the possibility of using saliva as a diagnostic alternative for blood. Whole saliva contains some components of plasma along with locally produced substances, which can be used for diagnostic purposes. It is well known that identifiable changes in the concentration of various components in saliva were induced during many of the systemic diseases. Saliva has been reported to contain many of the biomarkers used in diagnosis and management CKD. These include creatinine, urea, and uric acid. Keeping the above in view and considering the increased incidence of DM worldwide with limited studies carried out in saliva, we proposed to conduct a comparative and correlation study of the concentrations of salivary and blood parameters in $\mathrm{T} 2 \mathrm{D}$ patients.

The aim of the study was to analyze the correlation of blood and salivary renal biomarkers in healthy, T2D without nephropathy and T2D with nephropathy groups and evaluate the role of saliva as a non-invasive alternative diagnostic tool to blood.

\section{MATERIALS AND METHODS}

The kits for analysis were obtained from ERBA Diagnostics Mannheim GmbH (Germany) through Transasia Bio-Medicals Ltd. (India). $5 \mathrm{ml}$ syringe, fluoride tube and plain tube for blood collection and sterile container for saliva collection were used for the study.

\section{Subjects}

A total of one hundred and eighty patients (both male and female) were selected for the study. The subjects were of age between 30 to 78 years and divided into following three groups:

Group 1: A control group consists of 90 non-diabetic healthy individuals with no history of T2D.

Group 2: The group includes 45 T2D patients without any kidney problems.

Group 3: This group consists of 45 T2D patients with kidney problems.

Inclusion criteria for selection of subjects:

- Known T2D patients with a fasting blood glucose level $>110 \mathrm{mg} / \mathrm{dL}$.
- Known T2D patients with diabetic nephropathy.

- Randomly selected subjects with no history of diabetes were used as controls.

Exclusion criteria for selection of subjects:

- T1D patients

- Pregnant women

- Patients who either smoked or consumed alcohol in the last $24 \mathrm{~h}$

\section{Ethical clearance}

All the subjects were registered for the study on a convenient sampling basis. The approval of the Institutional Human Ethics Committee (IHEC number: MU-IHEC-2016-2) was obtained for this study.

\section{Sample collection}

All individuals were registered for the study on a convenient sampling basis. All subjects were informed clearly about the sampling methods. Blood and saliva samples were collected from all the subjects in the morning between 9.00 to $11.00 \mathrm{hrs}$ after overnight fasting.

\section{Saliva collection}

All the individuals are informed not to drink (except water) or chew gum during the fasting period. Initially, food particles in the mouth were removed by rinsing with water. Then, $5 \mathrm{ml}$ of unstimulated saliva was collected up to $5 \mathrm{~min}$ by following standard spitting method. Collected saliva was centrifuged at $3000 \mathrm{rpm}$ for $15 \mathrm{~min}$, and the supernatant was stored at $-20^{\circ} \mathrm{C}$ until further use.

\section{Blood collection}

Venous blood was collected under aseptic conditions from all the subjects. Totally $5 \mathrm{ml}$ of fasting venous blood was collected from all the subjects into separate tubes such as fluoride and plain tubes, which will be used for the estimation of blood glucose and renal function tests respectively. To prepare serum, blood was allowed to clot at room temperature up to $30 \mathrm{~min}$. After 30 minutes, blood was centrifuged at $3000 \mathrm{rpm}$ for $15 \mathrm{~min}$., and the supernatant was collected and stored at $-20^{\circ} \mathrm{C}$ until used.

\section{Instruments used}

CHEM5X semi-automated clinical chemistry analyzer

Analysis of glucose, urea, uric acid and creatinine in both saliva and serum samples were performed on this semi-automated Biochemistry analyzer procured from ERBA Diagnostics Mannheim GmbH (Germany).

\section{Quantification of glucose concentration}

The glucose was estimated using Trinder's method, based on glucose oxidation. 


\section{Renal function tests}

\section{Urea}

Concentration of urea in both blood and saliva samples of all the study subjects was measured using the kinetic and enzymatic methods as developed by Talke and Schubert.

\section{Creatinine}

Estimation of creatinine in both blood and saliva samples of all the three study group subjects were done using modified Jaffe's reaction.

\section{Uric acid}

Uric acid concentration in the samples (both blood and saliva) was estimated using a method based on Trinder's reaction.

\section{Statistical analysis}

Data were analyzed using statistical software SPSS (Statistical package for the social sciences) version 22. The significance was established upon a $\mathrm{P}<0.05$. Data were represented as mean \pm standard deviation (SD) for each group. The multiple comparisons of parameters between groups were carried out by performing Post Hoc Test. Paired T-test and Pearson's correlation test was used to compare and correlate blood and salivary biomarker levels between groups.

\section{RESULTS}

Earlier reports have confirmed the presence of glucose in both serum and saliva of diabetic patients. Hence, saliva can be used as a sample for the diagnosis of diabetes (10). In this study, 90 healthy (Group 1), 45 T2D without nephropathy (Group 2) and 45 T2D individuals with nephropathy (Group 3) were used. The correlation between levels of glucose in saliva and serum of all the three groups were evaluated. The levels of glucose in blood and saliva of all the group subjects are tabulated in Table 1.

The mean blood glucose level in Group 1 was observed to be $91.26 \pm 9.13 \mathrm{mg} / \mathrm{dL}$ (Table 1.). The observed mean blood glucose level in Group 2 and 3 were $138.44 \pm 44.60 \mathrm{mg} / \mathrm{dL}$ and $136.22 \pm 38.91$ $\mathrm{mg} / \mathrm{dL}$, respectively. In case of saliva, the mean glucose level of the healthy individuals was $4.21 \pm$ $0.48 \mathrm{mg} / \mathrm{dL}$, whereas the groups containing T2D patients without and with nephropathy showed mean glucose $5.61 \pm 0.90 \mathrm{mg} / \mathrm{dL}$ and $5.55 \pm 4.21 \mathrm{mg} / \mathrm{dL}$, respectively (Table 1 ).

The salivary and blood glucose levels are in agreement with each other. Diabetic without nephropathy group showed higher levels of glucose, which is followed by group with nephropathy and healthy individuals. Earlier studies also showed similar results with higher glucose levels in saliva samples of controlled diabetics and uncontrolled diabetics compared to control (10). The diffusion of glucose through semipermeable membrane (11) and changes in the salivary gland basement membrane $(12,13)$ are considered as the major reasons behind the presence of glucose in the saliva. The mean difference between the glucose levels in serum and glucose level in saliva samples (Table 2) of all the three group subjects were measured.

A significant difference was observed between the blood glucose levels of Group 1 and other two (Group 2 and 3 ) groups $(\mathrm{P}<0.001)$. However, no significant difference was noticed between Group 2 and 3 $(\mathrm{P}=0.935)$ (Table 2). In saliva also, we found a significant difference in the glucose levels between the healthy groups and other two groups, T2D without nephropathy and T2D with nephropathy groups $(\mathrm{P}<0.001)$. However, no significant difference was noticed between Group 2 and 3 ( $\mathrm{P}=0.890$; Table 2).

\section{Renal function tests}

In this study, we analyzed the biochemical parameters of renal function in both serum and saliva samples of healthy (Group 1), T2D without nephropathy (Group 2) and T2D with nephropathy subjects (Group 3). Tables 3 shows the serum and salivary biochemical parameters of renal function and Table 4 illustrates the multiple comparison of renal function parameters between groups in blood and saliva, respectively. Urea, uric acid, and creatinine were significantly higher in diabetes patients with nephropathy compared to diabetices without nephropathy and healthy groups.

\section{Urea}

The mean serum urea level in the Group 1 was estimated to be $22.16 \pm 7.10 \mathrm{mg} / \mathrm{dL}$. Serum urea level in T2D without nephropathy group was slightly increased to $24.46 \pm 8.13 \mathrm{mg} / \mathrm{dL}$. This level was significantly increased in case of Group 3 (T2D with nephropathy), which showed a mean value of $86.86 \pm$ $50.78 \mathrm{mg} / \mathrm{dL}$.

In case of saliva, mean urea in the Group 1 and 2 were $29.58 \pm 7.47 \mathrm{mg} / \mathrm{dL}$ and $31.73 \pm 8.38 \mathrm{mg} / \mathrm{dL}$, respectively. In the T2D with nephropathy group, the mean level of urea was increased remarkably to 96.77 $\pm 53.13 \mathrm{mg} / \mathrm{dL}$.

\section{Uric acid}

In serum, mean uric acid level in the non-diabetic group was $5.57 \pm 1.28 \mathrm{mg} / \mathrm{dL}$, which was slightly increased in Group $2(5.70 \pm 1.42 \mathrm{mg} / \mathrm{dL})$. The T2D with nephropathy group showed notable increase in the serum uric acid $(8.18 \pm 2.43 \mathrm{mg} / \mathrm{dL})$.

In case of saliva, the mean uric acid value in the nondiabetic and T2D without neuropathy groups was 0.77 $\pm 0.30 \mathrm{mg} / \mathrm{dL}$ and $0.89 \pm 0.42 \mathrm{mg} / \mathrm{dL}$, respectively. This level was increased significantly in case of T2D 
with nephropathy group $(1.20 \pm 0.79 \mathrm{mg} / \mathrm{dL})$, which was in agreement with that of serum.

\section{Creatinine}

The mean creatinine level in the serum of healthy group was $0.94 \pm 0.23 \mathrm{mg} / \mathrm{dL}$, which remained constant in T2D without nephropathy group (0.94 \pm $0.14 \mathrm{mg} / \mathrm{dL}$ ). However, Group 3 (T2D with nephropathy) showed increased level of creatinine $(4.17 \pm 2.53 \mathrm{mg} / \mathrm{dL})$.

The pattern of change in the creatinine levels of serum and saliva were similar. The salivary creatinine levels in both non-diabetic (Group 1) and T2D without nephropathy (Group 2) groups were found similar $(0.17 \pm 0.08 \mathrm{mg} / \mathrm{dL}$ and $0.16 \pm 0.05 \mathrm{mg} / \mathrm{dL}$, respectively). In case of the diabetic group with nephropathy, the mean creatinine value was increased to $0.469 \pm 0.16 \mathrm{mg} / \mathrm{dL}$.

\section{CORRELATION STUDIES}

The correlation of all the parameters in both blood and saliva was analyzed in healthy (Table 5), T2D without nephropathy (Table 6) and T2D with nephropathy (Table 7) groups.

\section{Blood glucose and salivary glucose}

A significant positive correlation was observed in both blood and salivary glucose level in all the three groups $(\mathrm{P}<0.001)$.

\section{Renal function tests}

Mean values of all the parameters of renal function differed significantly between blood and saliva $(\mathrm{P}<0.001)$ in all the three groups and there is a significant positive correlation between blood and saliva of all the variables $(\mathrm{P}<0.001)$.

Table 1: Comparison of blood and salivary glucose between groups

\begin{tabular}{|c|c|c|c|c|}
\hline Group & $\mathbf{n}$ & Mean Glucose & Standard Deviation & $P$ Value \\
\hline \multicolumn{5}{|c|}{ Blood glucose } \\
\hline Non-diabetics & 90 & 91.267 & 9.1354 & \multirow[t]{3}{*}{$<0.001 * *$} \\
\hline T2D without nephropathy & 45 & 138.444 & 44.6000 & \\
\hline T2D with nephropathy & 45 & 136.222 & 38.9148 & \\
\hline \multicolumn{5}{|c|}{ Salivary glucose } \\
\hline Non-diabetics & 90 & 4.2128 & 0.48370 & \multirow{3}{*}{$<0.001 * *$} \\
\hline T2D without nephropathy & 45 & 5.6191 & 0.90108 & \\
\hline T2D with nephropathy & 45 & 5.5500 & 0.87552 & \\
\hline
\end{tabular}

Table 2: Post Hoc test for multiple comparisons of blood and salivary glucose between groups

\begin{tabular}{|c|c|c|c|}
\hline Group (A) & Group (B) & $\begin{array}{c}\text { Mean Difference } \\
\text { (A-B) }\end{array}$ & P Value \\
\hline \multicolumn{4}{|c|}{ Blood glucose } \\
\hline \multirow{2}{*}{$\begin{array}{l}\text { T2D without } \\
\text { nephropathy }\end{array}$} & Non-diabetics & 47.1778 & $<0.001 * *$ \\
\hline & $\begin{array}{c}\text { T2D with } \\
\text { nephropathy }\end{array}$ & 2.2222 & 0.935 \\
\hline $\begin{array}{l}\text { T2D with } \\
\text { nephropathy }\end{array}$ & Non-diabetics & 44.9556 & $<0.001 * *$ \\
\hline \multicolumn{4}{|c|}{ Salivary glucose } \\
\hline \multirow{2}{*}{$\begin{array}{l}\text { T2D without } \\
\text { nephropathy }\end{array}$} & Non-diabetics & 1.40633 & $<0.001 * *$ \\
\hline & $\begin{array}{c}\text { T2D with } \\
\text { nephropathy }\end{array}$ & 0.06911 & 0.890 \\
\hline T2D with nephropathy & Non-diabetics & 1.33722 & $<0.001 * *$ \\
\hline
\end{tabular}

** Significant 
Table 3: Comparison of renal function tests in blood and saliva between groups

\begin{tabular}{|c|c|c|c|c|c|}
\hline Parameters & Group & $\mathbf{n}$ & Mean & Standard Deviation & P Value \\
\hline \multicolumn{6}{|c|}{ Blood sample } \\
\hline \multirow{3}{*}{$\begin{array}{c}\text { Urea } \\
(\mathrm{mg} / \mathrm{dL})\end{array}$} & Non-diabetics & 90 & 22.167 & 7.1032 & \multirow{3}{*}{$<0.001 * *$} \\
\hline & T2D without nephropathy & 45 & 24.467 & 8.1313 & \\
\hline & T2D with nephropathy & 45 & 86.867 & 50.7850 & \\
\hline \multirow{3}{*}{$\begin{array}{l}\text { Uric acid } \\
(\mathrm{mg} / \mathrm{dL})\end{array}$} & Non-diabetics & 90 & 5.5711 & 1.28947 & \multirow{3}{*}{$<0.001 * *$} \\
\hline & T2D without nephropathy & 45 & 5.7080 & 1.42665 & \\
\hline & T2D with nephropathy & 45 & 8.1887 & 2.43385 & \\
\hline \multirow{3}{*}{$\begin{array}{l}\text { Creatinine } \\
(\mathrm{mg} / \mathrm{dL})\end{array}$} & Non-diabetics & 90 & 0.94422 & 0.233252 & \multirow{3}{*}{$<0.001 * *$} \\
\hline & T2D without nephropathy & 45 & 0.94773 & 0.144447 & \\
\hline & T2D with nephropathy & 45 & 4.17400 & 2.534263 & \\
\hline \multicolumn{6}{|c|}{ Saliva sample } \\
\hline \multirow{3}{*}{$\begin{array}{c}\text { Urea } \\
(\mathrm{mg} / \mathrm{dL})\end{array}$} & Non-diabetics & 90 & 29.581 & 7.4726 & \multirow{3}{*}{$<0.001 * *$} \\
\hline & $\begin{array}{l}\text { T2D without } \\
\text { nephropathy }\end{array}$ & 45 & 31.738 & 8.3839 & \\
\hline & T2D with nephropathy & 45 & 96.776 & 53.1339 & \\
\hline \multirow{3}{*}{$\begin{array}{l}\text { Uric acid } \\
(\mathrm{mg} / \mathrm{dL})\end{array}$} & Non-diabetics & 90 & 0.7794 & 0.30279 & \multirow{3}{*}{$<0.001 * *$} \\
\hline & $\begin{array}{l}\text { T2D without } \\
\text { nephropathy }\end{array}$ & 45 & 0.8996 & 0.42480 & \\
\hline & T2D with nephropathy & 45 & 1.2064 & 0.79521 & \\
\hline \multirow{3}{*}{$\begin{array}{l}\text { Creatinine } \\
(\mathrm{mg} / \mathrm{dL})\end{array}$} & Non-diabetics & 90 & 0.1740 & 0.08534 & \multirow{3}{*}{$<0.001 * *$} \\
\hline & $\begin{array}{l}\text { T2D without } \\
\text { nephropathy }\end{array}$ & 45 & 0.1693 & 0.05726 & \\
\hline & T2D with nephropathy & 45 & 0.4691 & 0.16802 & \\
\hline
\end{tabular}

**Significant

Table 4: Post Hoc test for multiple comparison of renal function test in blood and saliva between groups

\begin{tabular}{|c|c|c|c|c|}
\hline Parameters & Group (A) & Group (B) & $\begin{array}{c}\text { Mean Difference } \\
\text { (A-B) }\end{array}$ & P Value \\
\hline \multicolumn{5}{|c|}{ Blood sample } \\
\hline \multirow{2}{*}{$\begin{array}{c}\text { Urea } \\
\text { (mg/dL) }\end{array}$} & T2D without nephropathy & T2D with nephropathy & -62.4000 & $<0.001^{* *}$ \\
\cline { 3 - 5 } & & Non-diabetics & 2.3000 & 0.880 \\
\cline { 2 - 5 } & T2D with nephropathy & Non-diabetics & 64.7000 & $<0.001^{* *}$ \\
\hline \multirow{2}{*}{$\begin{array}{c}\text { Uric acid } \\
(\mathrm{mg} / \mathrm{dL})\end{array}$} & T2D without nephropathy & T2D with nephropathy & -2.48067 & $<0.001^{* *}$ \\
\cline { 3 - 5 } & & Non-diabetics & 0.13689 & 0.896 \\
\cline { 2 - 5 } & T2D with nephropathy & Non-diabetics & 2.61756 & $<0.001^{* *}$ \\
\hline Creatinine & T2D without nephropathy & T2D with nephropathy & -3.226267 & $<0.001^{* *}$ \\
\hline
\end{tabular}




\begin{tabular}{|c|c|c|c|c|}
\hline \multirow{2}{*}{$(\mathrm{mg} / \mathrm{dL})$} & & Non-diabetics & 0.003511 & 1.000 \\
\cline { 2 - 5 } & T2D with nephropathy & Non-diabetics & 3.229778 & $<0.001 * *$ \\
\hline
\end{tabular}

\begin{tabular}{|c|c|c|c|c|}
\hline \multirow{2}{*}{$\begin{array}{c}\text { Urea } \\
(\mathrm{mg} / \mathrm{dL})\end{array}$} & T2D without nephropathy & T2D with nephropathy & -65.0378 & $<0.001 * *$ \\
\cline { 3 - 5 } & & Non-diabetics & 2.1567 & 0.902 \\
\cline { 2 - 5 } & T2D with nephropathy & Non-diabetics & 67.1944 & $<0.001 * *$ \\
\hline \multirow{2}{*}{$\begin{array}{c}\text { Uric acid } \\
(\mathrm{mg} / \mathrm{dL})\end{array}$} & T2D without nephropathy & T2D with nephropathy & -0.30689 & $0.011^{*}$ \\
\cline { 2 - 5 } & & Non-diabetics & 0.12011 & 0.386 \\
\cline { 2 - 5 } & T2D with nephropathy & Non-diabetics & 0.42700 & $<0.001 * *$ \\
\hline \multirow{2}{*}{$\begin{array}{c}\text { Creatinine } \\
(\mathrm{mg} / \mathrm{dL})\end{array}$} & T2D without nephropathy & T2D with nephropathy & -0.29978 & $<0.001 * *$ \\
\cline { 2 - 5 } & & Non-diabetics & -0.00467 & 0.969 \\
\cline { 2 - 5 } & T2D with nephropathy & Non-diabetics & 0.29511 & $<0.001 * *$ \\
\hline
\end{tabular}

**Significant

Table 5: Paired t-test and correlations for non-diabetics $(n=90)$

\begin{tabular}{|c|c|c|c|c|c|}
\hline Pair & Parameters & Mean & Standard Deviation & Correlation & P Value \\
\hline \multirow[t]{2}{*}{ Pair 1} & Glucose (Blood) & 91.267 & 9.1354 & \multirow[t]{2}{*}{0.808} & \multirow[t]{2}{*}{$<0.001 * *$} \\
\hline & Glucose (Saliva) & 4.2128 & 0.48370 & & \\
\hline \multirow[t]{2}{*}{ Pair 2} & Urea (Blood) & 22.167 & 7.1032 & \multirow[t]{2}{*}{0.994} & \multirow[t]{2}{*}{$<0.001 * *$} \\
\hline & Urea (Saliva) & 29.581 & 7.4726 & & \\
\hline \multirow[t]{2}{*}{ Pair 3} & Uric acid (Blood) & 5.5711 & 1.28947 & \multirow[t]{2}{*}{0.882} & \multirow[t]{2}{*}{$<0.001 * *$} \\
\hline & Uric acid (Saliva) & 0.7794 & 0.30279 & & \\
\hline \multirow[t]{2}{*}{ Pair 4} & Creatinine (Blood) & 0.94422 & 0.233252 & \multirow[t]{2}{*}{0.851} & \multirow[t]{2}{*}{$<0.001 * *$} \\
\hline & Creatinine (Saliva) & 0.1740 & 0.08534 & & \\
\hline
\end{tabular}

**Significant

Table 6: Paired T-test and correlations for T2D without nephropathy $(n=45)$

\begin{tabular}{|c|c|c|c|c|c|}
\hline Pair & Parameters & Mean & $\begin{array}{l}\text { Standard } \\
\text { Deviation }\end{array}$ & Correlation & $\begin{array}{c}\mathbf{P} \\
\text { Value }\end{array}$ \\
\hline \multirow[t]{2}{*}{ Pair 1} & Glucose (Blood) & 138.444 & 44.6000 & \multirow[t]{2}{*}{0.883} & \multirow{2}{*}{$\begin{array}{l}<0.001 \\
\quad * *\end{array}$} \\
\hline & Glucose (Saliva) & 5.6191 & 0.90108 & & \\
\hline \multirow[t]{2}{*}{ Pair 2} & Urea (Blood) & 24.467 & 8.1313 & \multirow[t]{2}{*}{0.995} & \multirow{2}{*}{$\begin{array}{c}<0.001 \\
* *\end{array}$} \\
\hline & Urea (Saliva) & 31.738 & 8.3839 & & \\
\hline \multirow[t]{2}{*}{ Pair 3} & Uric acid (Blood) & 5.7080 & 1.42665 & \multirow[t]{2}{*}{0.929} & \multirow{2}{*}{$\begin{array}{l}<0.001 \\
\quad * *\end{array}$} \\
\hline & Uric acid (Saliva) & 0.8996 & 0.42480 & & \\
\hline \multirow[t]{2}{*}{ Pair 4} & Creatinine (Blood) & 0.94773 & 0.144447 & \multirow[t]{2}{*}{0.880} & \multirow{2}{*}{$\begin{array}{c}<0.001 \\
* *\end{array}$} \\
\hline & Creatinine (Saliva) & 0.1693 & 0.05726 & & \\
\hline
\end{tabular}

**Significant

Table 7: Paired T-test and correlations for T2D with nephropathy $(n=45)$

\begin{tabular}{|l|l|l|l|l|l|}
\hline Pair & Parameters & Mean & Standard & Correlation & P \\
\hline
\end{tabular}




\begin{tabular}{|c|c|c|c|c|c|}
\hline & & & Deviation & & Value \\
\hline \multirow[t]{2}{*}{ Pair 1} & Glucose (Blood) & 136.222 & 38.9148 & \multirow[t]{2}{*}{0.929} & \multirow{2}{*}{$\begin{array}{c}<0.001 \\
* *\end{array}$} \\
\hline & Glucose (Saliva) & 5.5500 & 0.87552 & & \\
\hline \multirow[t]{2}{*}{ Pair 2} & Urea (Blood) & 86.867 & 50.7850 & \multirow[t]{2}{*}{0.999} & \multirow{2}{*}{$\begin{array}{c}<0.001 \\
* *\end{array}$} \\
\hline & Urea (Saliva) & 96.776 & 53.1339 & & \\
\hline \multirow[t]{2}{*}{ Pair 3} & Uric acid (Blood) & 8.1887 & 2.43385 & \multirow[t]{2}{*}{0.918} & \multirow{2}{*}{$\begin{array}{c}<0.001 \\
* *\end{array}$} \\
\hline & Uric acid (Saliva) & 1.2064 & 0.79521 & & \\
\hline \multirow[t]{2}{*}{ Pair 4} & $\begin{array}{l}\text { Creatinine } \\
\text { (Blood) }\end{array}$ & 4.17400 & 2.534263 & \multirow[t]{2}{*}{0.970} & \multirow[t]{2}{*}{$\begin{array}{l}<0.001 \\
* *\end{array}$} \\
\hline & $\begin{array}{c}\text { Creatinine } \\
\text { (Saliva) }\end{array}$ & 0.4691 & 0.16802 & & \\
\hline
\end{tabular}

**Significant

\section{DISCUSSION}

The results of the present study showed that the mean fasting blood glucose levels in diabetic group without and with nephropathy increased significantly (138.444 $\pm 44.60 \mathrm{mg} / \mathrm{dL}$ and $136.22 \pm 38.91$, respectively) when compared to healthy group $(91.267 \pm 9.13 \mathrm{mg} / \mathrm{dL})$. This trend is almost similar in saliva also with the glucose concentration of $4.21 \pm 0.48 \mathrm{mg} / \mathrm{dL}, 5.61 \pm$ $0.90 \mathrm{mg} / \mathrm{dL}$ and $5.55 \pm 0.87 \mathrm{mg} / \mathrm{dL}$ in non-diabetic, T2D without nephropathy and T2D with nephropathy groups, respectively. Various other studies have also reported similar results $(5,14-17)$. However, Vaziri and colleagues have reported contradictory results with no significant difference between salivary glucose concentrations of healthy and diabetics (18).

Previous studies have showed that, increased levels of plasma glucose led to influx of glucose into saliva through semi-permeable membrane $(19,20)$. As a result, increased levels of glucose were observed in saliva during diabetes. In our study, a highly positive correlation between salivary and plasma glucose in healthy, diabetic patients without and with nephropathy was observed. These correlations were found to be statistically significant. Hence, it can be stated that salivary glucose can be used as an indicator of serum glucose concentration in diabetic patients. These results were in agreement with some of the earlier reports of $(5,14$, and 16$)$.

Results of our study showed a significant difference in salivary and plasma glucose between healthy and T2D groups (both without and with nephropathy) $(\mathrm{p}=0.001)$ which are on the similar lines with that of the findings from other laboratories $(5,11,21)$. No significant difference in salivary and plasma glucose was observed between T2D with nephropathy and T2D without nephropathy groups, which may be due to the confounding factors of hypoglycemic treatments. Compared to many previous studies, our study has shown significant positive correlation between salivary and plasma glucose in all the groups. These findings are in accordance with the many of the studies reported earlier $(11,20-22)$.

The major hallmarks of CKD involve increased levels of biochemical parameters such as urea, creatinine, potassium, phosphorus, uric acid, and decreased calcium in blood. Thus, these biochemical parameters were estimated frequently for the better management of CKD. This leads to the psychological trauma in the patients, because of the repeated blood collections, therefore arising the requirement for alternative biological fluid. Saliva is considered alternative diagnostic fluid of choice for many clinical situations (23) including renal disease.

In current study, biochemical parameters, which are used in monitoring kidney failure, were evaluated in both serum and saliva. The group with T2D patients with nephropathy showed increased salivary and serum creatinine levels compared to healthy and T2D without renal failure groups. Previous reports have also showed similar results $(24,25)$, with serum levels of creatinine reflecting with that of saliva (26). In all the three groups, a positive correlation was observed between serum and salivary creatinine levels ( $\mathrm{P}<0.0001)$. The concentration of creatinine in saliva is much lower than serum, which is in agreement with earlier reports $(24,25)$. Such decreased levels of creatinine in saliva are due to incomplete infiltration of relatively non-polar creatinine from blood. Thus, the salivary levels of creatinine are $10-15 \%$ of serum $(27,28)$. Reports have supported the use of saliva instead of serum to estimate creatinine in diagnosing renal failure. However, a cut-off value of >14.6 $\mu \mathrm{mol} / \mathrm{L}$ with a sensitivity and specificity of 100 and $98.3 \%$, respectively has been proposed to identify kidney failure patients (29). Two other independent findings have proposed the cut-off of $11.33 \mu \mathrm{mol} / \mathrm{L}$ and $16.8 \mu \mathrm{mol} / \mathrm{L}$ for using saliva as the diagnostic sample $(24,27)$.

Results of our study showed elevated levels of serum and salivary urea in T2D with nephropathy patients 
(Group 3; p <0.001) compared to other two groups (healthy and T2D without nephropathy). This is in agreement with results of previous studies reported earlier (24). Results showed that the salivary levels of the urea were higher than serum, as the urea was transported from blood to saliva by passive diffusion (30). As observed in previous reports (24), a positive correlation in urea level was observed between saliva and serum $(\mathrm{P}<0.0001)$. Salivary creatinine and urea levels were positively correlated with serum levels, especially in patients with end stage renal disease. The values found were having high sensitivity and specificity, thus supporting the possibility of using saliva in the diagnosis and monitoring of patients with CKD (31). It was earlier proposed that the salivary urea and creatinine levels along with the eGFR value calculated from salivary creatinine levels can be used as the biochemical marker in differentiating kidney failure patients form healthy individuals (29).

Many reports have confirmed the presence of uric acid in saliva with a linear relationship with that of serum levels $(32,33)$. In our study, we have observed statistically significant difference in salivary uric acid levels between the control group $(0.77 \pm 0.30)$, diabetic patients without nephropathy $(0.89 \pm 0.42)$, and diabetics with nephropathy $(1.20 \pm 0.79)$ with $\mathrm{p}<$ 0.001 . This is in agreement with two earlier independent findings, which reported the significant increase in the salivary uric acid in patients with metabolic syndrome (32) and ESRD (33). We also observed a correlation between serum and salivary uric acid in all the three groups.

\section{CONCLUSION}

The present study aimed at developing a non-invasive method to diagnose and manage diabetes. This study confirmed that many of the parameters studied in both blood and saliva showed good positive correlation. The study confirmed that the saliva can be very potential diagnostic tool to diagnose and manage diabetes and its complications. Therefore, saliva can be effectively used as a sample for measuring and controlling diabetes in near future.

CONFLICT OF INTEREST: Authors declare no conflict of interest.

\section{REFERENCES}

1. Deepthi, B., Sowjanya, K., Lidiya, B., Bhargavi, R. S., Babu, P. S. A modern review of diabetes mellitus: an annihilatory metabolic disorder. Journal of In Silico \& In Vitro Pharmacology. 2017; 3(1). doi:10.21767/2469-6692.100014

2. Dipti, K. H., Maitreyee, D. S., Shivashankara, A. R., Avinash, S. S., Malathi, M. A correlative study of salivary and plasma glucose levels in type 2 diabetic patients with and without complications. International Journal of Clinical Biochemistry and Research. 2016; 3(2): 250-254.

3. Baynest, H. W. Classification, pathophysiology, diagnosis and management of diabetes mellitus. Journal of Diabetes \& Metabolism. 2015; 6(5): 1-9. doi:10.4172/2155$\underline{6156.1000541 .}$
4. Gong, S., Guo, J., Han, X., Li, M., Zhou, L., Cai, X., et al. Clinical and genetic features of patients with type 2 diabetes and renal glycosuria. J Clin Endocrinol Metab. 2017; 102(5): 1548-1556. doi:10.1210/jc.2016-2332

5. Abikshyeet, P., Ramesh, V., Oza, N. Glucose estimation in the salivary secretion of diabetes mellitus patients. Diabetes Metab Syndr Obes. 2012; 5:149-154. doi:10.2147/DMSO.S32112

6. Nagarathinam, A. E., Kumar, T. D., Kumar, A. R., Vasanthira, K., Lakshmi, R. S., Jayant, V. S. Salivary urea and creatinine as a diagnostic marker of chronic kidney disease - review. IOSR Journal of Dental and Medical Sciences. 2017; 16: 95-100. doi:10.9790/0853-16040995100

7. Suresh, G., Ravi Kiran, A., Samata, Y., Purnachandrarao Naik N, Vijay Kumar A. Analysis of blood and salivary urea levels in patients undergoing haemodialysis and kidney transplant. J Clin Diagn Res. 2014; 8(7): ZC18-ZC20. doi:10.7860/JCDR/2014/8081.4553

8. Singh, S., Ramesh, V., Oza, N., Balamurali, P. D., Prashad, K. V., Balakrishnan, P. Evaluation of serum and salivary lipid profile: A correlative study. J Oral Maxillofac Pathol. 2014;18(1):4-8. doi:10.4103/0973-029X.131881.

9. Kadashetti, V., Baad, R., Malik, N., Shivakumar, K. M., Vibhute, N., Belgaumi, U., et al. Glucose level estimation in diabetes mellitus by saliva: a bloodless revolution. Rom J Intern Med. 2015; 53(3): 248-252. doi:10.1515/rjim-2015$\underline{0032}$

10. Kumar, S., Padmashree, S., Jayalekshmi, R. Correlation of salivary glucose, blood glucose and oral candidal carriage in the saliva of type 2 diabetics: A case-control study. Contemp Clin Dent. 2014;5(3):312-317. doi:10.4103/0976237X.137925

11. Satish, B. N. V. S., Srikala, P., Maharudrappa, B., Awanti, S. M., Kumar, P., Hugar, D. Saliva: A tool in assessing glucose levels in Diabetes Mellitus. J Int Oral Health. 2014;6(2):114117.

12. Ladgotra, A., Verma, P., Raj, S. S. Estimation of salivary and serum biomarkers in diabetic and non-diabetic patients - a comparative study. J Clin Diagn Res. 2016; 10(6): 56-61. doi:10.7860/JCDR/2016/19135.7995

13. Reena, C. S., Indira, A. P., David, M. P. Evaluation of Salivary Albumin in Type II Diabetes Mellitus. International Journal of Contemporary Medical Research 2017; 4(6): 13641366.

14. Panchbhai, A. S., Degwekar, S. S., Bhowte, R. R. Estimation of salivary glucose, salivary amylase, salivary total protein and salivary flow rate in diabetics in India. J Oral Sci. 2010; 52(3): 359-368.

15. Priya, S. S., Bharani, G. O., Nagalingam, M., Jayanthi, M., Kanagavalli, U. Potential of salivary protein as a biomarker in prognosis of diabetes mellitus. Journal of Pharmacy Research 2011; 4(7); 2228-2229.

16. Agrawal, R. P., Sharma, N., Rathore, M. S., Gupta, V. B., Jain, S., Agarwal, V., et al. Noninvasive method for glucose level estimation by saliva. Journal of Diabetes \& Metabolism. 2013;04. doi:10.4172/2155-6156.1000266

17. Ivanovski, K., Naumovski, V., Kostadinova, M., Pesevska, S., Drijanska, K., Filipce, V. Xerostomia and salivary levels of glucose and urea in patients with diabetes. Prilozi. 2012; 33(2): 219-229.

18. Bakianian Vaziri, P., Vahedi, M., Mortazavi, H., Abdollahzadeh, S. h., Hajilooi, M. Evaluation of salivary glucose, IgA and flow rate in diabetic patients: A case-control study. J Dent (Tehran). 2010; 7(1): 13-18.

19. Harrison, R., Bowen, W. H. Flow rate and organic constituents of whole saliva in insulin-dependent diabetic children and adolescents. Pediatr Dent. 1987; 9(4): 287-291.

20. Nagalaxmi, V., Priyanka, V. Can saliva be a marker for predicting type 1 diabetes mellitus?-a pilot study. Journal of Indian Academy of Oral Medicine and Radiology. 2011; 23: 579-582. doi:10.5005/jp-journals-10011-1226 
21. Mirzaii-Dizgah, I., Mirzaii-Dizgah, M. R., Mirzaii-Dizgah, M. H. Stimulated saliva glucose as a diagnostic specimen for detection of diabetes mellitus. J Arch Mil Med. 2013; 1: 2427.

22. Hegde, A., Shenoy, R., D’Mello, P., Smitha, A., Tintu, A., Manjrekar, P. Alternative markers of glycemic status in diabetes mellitus. Biomedical Research. 2010; 21(3).

23. Malamud, D., Rodriguez-Chavez, I. R. Saliva as a diagnostic fluid. Dent Clin North Am. 2011; 55(1): 159-178. doi:10.1016/j.cden.2010.08.004

24. Xia, Y., Peng, C., Zhou, Z., Cheng, P., Sun, L., Peng, Y., et al. Clinical significance of salivary urea, creatinine, and uric acid levels in patients with chronic kidney disease (Doctoral dissertation). $\quad 2012 ; \quad 37(11)$ : $\quad 1171-1176$. doi:10.3969/j.issn.1672-7347.2012.11.016

25. Venkatapathy, R., Govindarajan, V., Oza, N., Parameswaran, S., Pennagaram Dhanasekaran, B., Prashad, K. V. Salivary creatinine estimation as an alternative to serum creatinine in chronic kidney disease patients. Int J Nephrol. 2014; 2014:742724. doi: $10.1155 / 2014 / 742724$

26. Ladell, W. S. S. Creatinine losses in the sweat during work in hot humid environments. J Physiol. 1947; 106(3): 237-244.

27. Lloyd, J. E., Broughton, A., Selby, C. Salivary creatinine assays as a potential screen for renal disease. Ann Clin Biochem. 1996; $33 \quad(\mathrm{Pt}$ 5): $428-431$. doi: $10.1177 / 000456329603300505$

28. Chiou, W. L., Pu, F. S. Creatinine VIII: saliva levels of endogenous "true" creatinine in normal subjects. Clin Pharmacol Ther. 1979; 25(6): 777-782. doi:10.1002/cpt1979256777

29. Yajamanam, N., Vinapamula, K. S., Sivakumar, V., Bitla, A. R., Rao, P. V. L. N. S. Utility of saliva as a sample to assess renal function and estimated glomerular filtration rate. Saudi J Kidney Dis Transpl. 2016; 27(2): 312-319. doi: $10.4103 / 1319-2442.178549$

30. Carco, P., Canciullo, D. Urea excretion through the human salivary glands. Ann Otol Rhinol Laryngol. 1958 ;67(4): 1050-1065. doi: $10.1177 / 000348945806700414$

31. Shannon, I. L., Feller, R. P., Eknoyan, G., Suddick, R. P. Human parotid saliva urea in renal failure and during dialysis. Arch Oral Biol. 1977; 22(2): 83-86. doi:10.1016/00039969(77)90082-6.

32. Soukup, M., Biesiada, I., Henderson, A., Idowu, B., Rodeback, D., Ridpath, L., et al. Salivary uric acid as a noninvasive biomarker of metabolic syndrome. Diabetol Metab Syndr. 2012;4(1):14. doi:10.1186/1758-5996-4-14

33. Hadi, B.A., Al-Jubouri, R. H. Salivary and plasma analysis of oxidative stress biomarkers in end stage renal failure patients. Journal of Baghdad college of dentistry. 2011; 23(2): 46-50. 